Fecha de recepción: febrero 2018 Fecha de aceptación: abril 2018 Versión final: diciembre 2019

\section{El presente y el irremediable pasado. La reconstrucción de lo público desde la música rap de la Alianza Urbana en Quibdó-Chocó, Colombia}

Andrea del Pilar Forero Hurtado*, Yulieth Aldana

Orozco $^{\star *}$ y Luis Carlos Rodríguez Páez ${ }^{* * *}$

Resumen: Chocó es un departamento colombiano que ha vivido en medio de una profunda crisis humanitaria. En su capital, Quibdó, un grupo de jóvenes crearon el programa "Alza tu voz", el cual dio nacimiento al grupo de música "Alianza Urbana". El presente texto busca exponer desde la perspectiva de la comunicación, las estrategias artísticas y pedagógicas constituidas por este colectivo para generar alternativas de vida, en un territorio donde los jóvenes parecen estancados en el tiempo, pero haciendo resistencia a situaciones del pasado con ritmos contemporáneos.

Palabras clave: Comunicación - Desarrollo y Cambio Social - Reconstrucción de lo Público - Prácticas Comunicativas.

[Resúmenes en francés, inglés y portugués en la página 81]

${ }^{(*)}$ Comunicadora Social y Periodista de la Universidad Externado de Colombia. Magister en Comunicación Educativa y Estudiante del Doctorado en Comunicación de la Universidad Nacional de la Plata -UNLP-. Docente del área de Comunicación y Participación de la Facultad de Ciencias de la Comunicación, Líder de semillero e investigadora social, miembro del grupo Comunicación, Lenguaje y Participación de la misma Facultad y Coordinadora del GT Arte y Política de CLACSO.

${ }^{* *}$ Comunicadora Social y Periodista de la Corporación Universitaria Minuto de Dios -UNIMINUTO-, Colombia. Estudiante del Doctorado en Comunicación de la Universidad Nacional de la Plata UNLP - Argentina. Líder del área de investigación, de la Facultad de Ciencias de la Comunicación e Investigadora miembro del grupo Comunicación, Lenguaje y Participación de la misma Facultad.

${ }^{(* *)}$ Comunicador Social y Periodista de la Corporación Universitaria Minuto de Dios -UNIMINUTO-, Colombia. Estudiante del Doctorado en Comunicación de la Universidad Nacional de la Plata -UNLP-. Docente del área de Comunicación y Contexto, de la Facultad de Ciencias de la Comunicación e Investigador miembro del grupo Comunicación, Lenguaje y Participación de la misma Facultad. 


\section{Introducción}

El estudio sobre lo público ha sido abordado por distintas disciplinas que han nacido producto de la reflexión crítica y la tarea de entender -por parte de sociólogos, filósofos, politólogos, antropólogos y administradores públicos, entre otros-, su vínculo con los asuntos privados.

Algunos debates sobre este tema se definen en virtud de su relación antagónica. Hanna Arendt (1993) argumenta que el vínculo entre lo público y privado no nace propiamente en la sociedad moderna occidental. En concordancia con ello, Bautista (2003) da cuenta que surge en la civilización griega. "Para los griegos lo público es el complemento de lo privado y posibilita la vida en comunidad a través del ejercicio de la política en la polis, organización fundamental e ideal de la vida en comunidad" (Bautista, 2003, p. 105)

De esta manera, lo público se aborda como algo distinto a lo estatal y a lo privado siendo un lugar social en el que se juntan los miembros de una comunidad para construirlo políticamente (Arendt, 1993, p. 17). Dicho de otra manera, si lo público es un ámbito social en el que sus actores organizan políticamente su comunidad, a partir de allí, podemos decir también que es un espacio social de mediación entre la sociedad civil y el Estado. Pero contrario a lo antes dicho, el afán modernizador y desarrollista de los años '60 de la sociedad occidental y posteriormente, su crisis en la década de los años '70 generó una contraposición entre ambos ámbitos. En la sociedad moderna estos aspectos son escenarios opuestos, "pues resulta funcional a determinados intereses políticos que se convierten en hegemónicos al interior de la sociedad” (Bautista, 2003, p. 105).

Bautista (2003) sugiere que el origen de esta visión contrapuesta de lo público y lo privado puede establecerse en la promoción del individualismo metodológico y en los principios de libertad y justicia que de tal noción se desprenden. Es decir, los asuntos privados son representados por los intereses individuales, los cuales deben primar sobre los objetivos públicos, dado que estos últimos encarnan a la comunidad o al conjunto social. De esta forma se garantiza que el individuo sea realmente un ser libre pues en últimas, los intereses públicos se construyen mediante la suma de los privados. "Así se concibe que el individuo es el constructor de la sociedad, la cual no es más que la suma de individuos". (Bautista, 2003, p. 105).

Esto último nos parece esclarecedor porque, evidentemente, la sociedad aún mantiene algunos rasgos de esta visión de lo público y lo privado. Nuestra realidad es un escenario donde la potencialidad del individuo "libre" es clave en el desarrollo económico de los países. En Colombia cada quien, debe aportar al sostenimiento económico del sistema estatal, pese a que el mismo produzca desconfianza por diferentes razones. Sin embargo, el sujeto es libre porque cada cual decide la manera en que se preocupa y ocupa de su propio bienestar y, por ende, de toda la sociedad. En esta línea, el mercado juega un papel importante porque

El interés del mercado es el verdadero interés público, pues únicamente en la esfera mercantil se da el proceso de elección libre y racional que requiere la construcción de lo público por fuera de los intereses políticos particulares, sea de individuos o de grupos sociales (Bautista, 2003, p. 106). 
En esa dirección, Fander Falconí (2014) plantea que la crisis del actual orden mundial económico del capitalismo es resultado del modelo de vida de la sociedad occidental. Para Falconí, este modelo fue gestándose bajo una lógica de mercado -ganancia y acumulación material-, producto de un individualismo extremo que transformó la vida y la conducta de los seres humanos. "Esto supone que la crisis civilizatoria del capitalismo occidental es el resultado de un modelo de sociedad basado en un profundo egoísmo que anula, en los hechos constatables, la solidaridad y la búsqueda del bien común del conglomerado humano" (Falconí, 2014, p. 22). Para los economistas clásicos, el Estado es una institución que hace parte del escenario social, cuya función gira en torno a la promoción o regulación de las necesidades que asigne el mercado.

Por su parte, Antanas Mockus (2002), afirma que lo público encarnó en el Estado, ya que la sociedad del S. XIX vio en él un instrumento de representación válido, eficaz y confiable con el cual poder materializar y llevar a la práctica las necesidades que la discusión pública destinaba como prioritarias. Pese a las buenas intenciones, esta nueva responsabilidad de lo público en el Estado contó con un sinnúmero de limitaciones y dificultades, las cuales en el S. XX crearon la necesidad de definir lo público como algo más allá de lo estatal.

Dadas las funciones del Estado como representante de los asuntos públicos -que a su vez originaron crisis y dificultades-, se buscó que su acción fuera críticamente vigilada por la sociedad civil. "Todos fueron invitados a ser jueces estatales, jueces de la acción estatal, delegatorias que debían cumplir un control sobre las instancias a las cuales se les había delegado la función de cumplir y administrar esos bienes de la nación" (Mokus, 2002, p. 13). Según Habermas, la idea de esfera pública

Designa un escenario en las sociedades modernas en el cual la participación política se realiza por medio del diálogo. Es el espacio en el cual los ciudadanos piensan y examinan sus asuntos comunes y por lo tanto es un escenario institucionalizado de interacción discursiva (Habermas, 1981, en Fraser, 2015, p. 12).

Para Habermas (2008), el espacio público no se aísla de los asuntos privados; por el contrario, plantea que su relevancia reside esencialmente en la racionalidad inscrita en las prácticas comunicativas cotidianas. En esa dirección, este investigador entiende lo público como un escenario en el que se originan y transitan relaciones discursivas, con las cuales se dinamiza el debate y la deliberación sobre los asuntos comunes. Esta perspectiva es bien distinta a la concepción arriba mencionada por Bautista (2003). La diferencia reside en que para el primero las relaciones construidas en el ámbito público no son económicas -de compra, venta o transacciones financieras-, sino discursivas y políticas y que pueden llegar hacer construcciones colectivas críticas frente al Estado. Tanto para Arenth (1993) como para Habermas (2008), los escenarios públicos y privados -aunque distintos-, son complementarios y no contrapuestos.

Nos parece relevante mencionar también, lo que Daniel Pécaut (2015) concibe como lo público. Para él, esta categoría tiene que ver con:

1. La aceptación de un principio de "semejanza" entre todos los miembros de la sociedad; esto en la visión de lo que Tocqueville llamaba el "principio ge- 
nerador" de las sociedades modernas es el reconocimiento de la "igualdad de condiciones" y del "derecho a tener derechos".

2. La visibilidad de los debates en un espacio no "organizado" por el Estado: así, aunque mantenga sus lazos con el mundo real no tiene que estar en contacto directo con los "intereses" y otras expresiones de inmediatez de distintos sectores de la población.

3. Un proceso argumentativo que busca darles validez general a los razonamientos recónditos expresados en la posición concreta de los participantes.

4. Una distancia con la política institucional. En buena medida esto obedece a la influencia de la "sociedad civil", entendida como una sociedad relativamente autónoma con respecto a las estructuras institucionales políticas. Habermas habla del "espacio público político" -lo público implica cierta relación con lo político- pero, sobre todo, insiste en su imbricación con la "sociedad civil".

5. El reconocimiento de un "mundo común" en cuyo seno se construyen las particularidades de grupos con diferentes tipos de identidad. Así, se puede afirmar que el espacio público es el lugar y el tema del "vivir juntos", que no niega las particularidades sino que las trasciende al asumir un mundo común (Pécaut, 2015, p. 3).

Si bien coincidimos con algunos de los planteamientos hechos por Pécaut (2015), debemos decir que pensamos que hoy, "lo común" en el escenario público requiere del reconocimiento de la diferencia. El vivir juntos implica comprender las tensiones que se originan entre los actores sociales, en sus prácticas comunicativas cotidianas. De tal modo "lo común" debería girar en torno al reconocimiento de la diversidad y no en la aceptación de la semejanza bajo el disfraz de la igualdad de condiciones. La convivencia requiere entonces poner las diferencias, más que las semejanzas, en el escenario público.

Creemos que es necesaria la visibilidad de los debates, pero sobre todo de la deliberación en el escenario público organizado y no organizado por el Estado porque con ello, los actores sociales ganan legitimidad, confianza en sí mismos, reconocimiento político, para la reconfiguración de su capital social. De todas maneras, en nuestra opinión, es ineludible la relación directa entre los distintos sectores de la sociedad y los diferentes capitales simbólicos. Pues de esta forma se entenderían de manera más real y profunda las lógicas, apuestas e intereses circulantes en la escena pública.

Advertimos la importancia de estas miradas sobre lo público porque en ellas se forja un espacio de participación política, en el que circulan intereses individuales y colectivos mediante el debate público, el cual se dinamiza a través del diálogo. Desde allí, la comunicación comienza a jugar un papel fundamental, pues en su práctica los ciudadanos y ciudadanas tienen la posibilidad de reflexionar y actuar colectivamente sobre las problemáticas y conflictos que afectan su cotidianidad. Por tanto es un espacio de apuestas políticas que constantemente se reconstruyen o reconfiguran dinámicamente, gracias a las relaciones establecidas entre los actores involucrados y a los intereses en juego sobre la arena pública. En este marco, distintos movimientos y organizaciones sociales gestaron diversas prácticas comunicativas que nacieron en el escenario social, en busca de legitimidad, reivindicación y reconocimiento político. Sus propuestas de comunicación popular y alternativa, mate- 
rializadas mediante experiencias colectivas y de los medios masivos, se sincronizaron con este tipo de comunicación para el desarrollo siendo parte de la cultura y el conocimiento local, en aras del fortalecimiento y dinamización de la organización política y social.

Este artículo tiene como propósito indagar sobre las temporalidades para la reconstrucción del espacio público del departamento de Chocó, Colombia, mediante una mirada comunicacional de las prácticas musicales llevadas a cabo por el grupo de rap: la Alianza Urbana. Para ello, daremos cuenta sobre los cambios de paradigma en el concepto de comunicación para comprender cómo a partir del reconocimiento de la materialidad histórica se efectúan acciones estéticas y participativas que evidencian y denuncian el presente de una población.

\section{Comunicación y desarrollo para el cambio social}

Abordar éste enfoque de la comunicación requiere dar una mirada a las raíces de la práctica comunicativa latinoamericana. Esto implica navegar por la historia política, económica y cultural para comprender sus aportes, contradicciones y nuevos desafíos en la época actual. Durante la década del '50 hasta mediados de los años '70, los aportes de Luis Ramiro Beltrán (2005) -considerado por muchos su pionero en América Latina-, tuvieron que ver con la crítica a la dependencia de la comunicación latinoamericana sobre las condiciones del poder económico y político trasnacional de los Estados Unidos.

La crítica de fondo poseía la intención de problematizar el papel de la comunicación unidireccional, en la generación de desarrollo y, por otro lado, el de propiciar la discusión sobre la incidencia de este modelo en las condiciones sociopolíticas y económicas de la región.

Claramente la comunicación unidireccional arriba señalada fue vigente en Latinoamérica, hasta bien entrada la década del '50. Hasta entonces la comunicación se entendía como una actividad que debía apoyar el desarrollo y, en esa línea, la postura unidireccional en si misma encarnaba la persuasión por parte de los medios masivos de comunicación que se constituyeron en uno de los pilares para el cambio de conductas individuales y colectivas mediante la publicidad.

La comunicación fundada sobre los planteos del paradigma dominante reforzaría su quehacer instrumental en la obtención del desarrollo. La comunicación aquí imaginada tenía por objeto impulsar el desarrollo rural, usándose para la enseñanza y promoción de habilidades. De esa manera, se empleó como una estrategia económica capaz de contribuir en temas como educación, salud e información. Bajo estas condiciones se beneficiaba más la esfera privada y no tanto a la pública dejando de lado, la promoción de habilidades de los campesinos, dado que éstos estaban mas próximos a los hábitos y destrezas técnicas de producción agrícola en áreas rurales, y no tanto con una formación crítica, política y participativa.

Dado todo lo anterior y en medio de muchas pugnas y luchas de poder se fue constituyendo una nueva perspectiva de la comunicación en Latinoamérica. Al respecto, Luis Ramiro Beltrán (2005) pensaba que la crisis del paradigma dominante se hallaba en el imaginario de la comunicación como única productora de desarrollo, sin advertir el contexto social, político, económico y cultural. Para ello se requirió reorientar no sólo la manera desordenada, descontextualizada y vertical de la idea modernizadora sino también, discutir a 
fondo el modelo clásico desarrollista copiado y materializado en la región. Como se puede notar lo común en estas definiciones es la idea de proceso, en tanto elemento relacional, constitutivo y de permanencia temporal de la comunicación, y del desarrollo en el que la participación, el diálogo y la horizontalidad encarnan el sentido de lo público en las prácticas alternativas y por ende de resistencia.

Distintos movimientos y organizaciones sociales gestaron diversas prácticas comunicativas que nacieron en el escenario social y político latinoamericano, en busca de legitimidad, reivindicación y reconocimiento político. Sus propuestas de comunicación popular y alternativa, materializadas a través de experiencias colectivas y de los medios masivos, se sincronizaron con este tipo de comunicación para el desarrollo, dado que ella acogía la cultura y el conocimiento local, en aras del fortalecimiento y dinamización de la organización política y social.

Ya entrada la década de los años '90 se acuñó un nuevo paradigma participativo impulsado por Alfonso Gumucio (2011), quien intentó -recogiendo los aportes realizados por importantes académicos como Paulo Freire, Juan Díaz Bordenave y Antonio Pascuali-, darle una nueva perspectiva a la comunicación para el desarrollo. Este nuevo impulso es conocido como Comunicación para el Cambio Social, que fuera definido por su autor como: "un proceso de diálogo y debate, basado en la tolerancia, el respeto, la equidad, la justicia social y la participación de todos" (Gumucio, 2011, p. 32).

Según Gumucio (2011), la comunicación para el cambio social hereda de la comunicación para el desarrollo su inquietud por el fortalecimiento de la organización social, la cultura, las tradiciones comunitarias y los saberes locales. La diferencia con los planteamientos de Beltrán (2005), según Gumucio, residen en que esta nueva apuesta comunicativa no pretende imponer a las comunidades ni las técnicas, ni los medios, ni muchos menos los mensajes, porque tanto las acciones como las propuestas deben salir directamente del universo comunitario.

A su vez, Rosa María Alfaro (2015), también durante la década de los '90, propuso otra forma de entender este tipo de experiencia. Para ella, la comunicación está directamente ligada a los procesos de desarrollo no de manera metodológica, sino como objetivo mismo de transformación tanto de la sociedad como de los individuos que la componen. Parte de un concepto de desarrollo no centrado exclusivamente en lo económico, aunque reconoce que su relación es necesaria. Por tanto, asume "la profunda interrelación entre las diversas dimensiones de la vida social, es decir, la economía, lo social, los procesos culturales y la política, donde los sujetos humanos debieran decidir y conducir el tipo de sociedad que deseen producir, con libertad" (Alfaro, 2015, p. 11).

Su apuesta se centra, muy de la mano con el planteamiento de Gumucio (2011), en el papel de la ciudadanía en los procesos de desarrollo, pues es ella quien debe ser protagonista en tales procesos. En ese sentido, la participación política de los ciudadanos y ciudadanas en el escenario público, es el eje central de la comunicación y el desarrollo. Para la autora, si la ciudadanía no se siente parte de los asuntos públicos, difícilmente se harán cargo de ellos. Siguiendo su enfoque, la comunicación y el desarrollo para el cambio social poseen algunos elementos que consideramos claves, los cuales hemos ido identificando durante nuestra participación en proyectos de investigación con diversos colectivos de trabajo. Aquí sólo mencionaremos algunos de ellos: 
La primera es la relación comunicativa propiamente dicha entre los sujetos sociales. Nos referimos a las relaciones comunicativas, humanas y sociales: como la posibilidad de interlocutar con los diferentes, de establecer interacciones e interrelaciones que beneficien a la sociedad en su conjunto. La segunda relación es con el territorio. Un territorio no se define por la espacialidad, ni por la cantidad de acres ni por el desalojo o abandono. Los territorios implican significación y constituyen los entornos que garantizan las subjetividades de los colectivos y la pervivencia y soportes de existencia de las colectividades. Otro propósito clave de esta comunicación es la generación de capital social para que se pueda construir lo público. Lo público necesita dolientes, ciudadanos interesados en esa esfera y articulados para ese propósito. El tercer elemento, es una comunicación que se asume como conflictiva. Los procesos sociales están llenos de contradicciones, de dificultades, y, por supuesto, de conflictos. La comunicación para el desarrollo asume los conflictos como parte de su acción y no como una situación anómala. El último elemento tiene que ver con el reconocimiento. Aquí el reconocimiento no es más un registro o una concesión, sino un proceso de doble vía, en el cual los sujetos se asumen como interlocutores y por eso se incluyen mutuamente. Sin reconocimiento entre los sujetos sociales no es posible comunicación alguna, y menos una que pretenda transformar las realidades existentes. Sólo habrá un cambio social significativo y legítimo si aprendemos a reconocernos entre todos (Rocha, Rodríguez, y Aldana, 2012, s/p. Congreso ALAIC).

Bajo estos principios valdría preguntarse ¿de qué manera incide la comunicación y el desarrollo en la construcción de lo público? A nuestro juicio, tanto la comunicación como el desarrollo son dimensiones que producen y promueven el conocimiento, la emancipación, la organización y participación política en el que se tiene la posibilidad de propiciar más procesos que productos. De tal manera, en ellos los medios masivos de comunicación son sólo instrumentos. Debido a ello, la comunicación es un proceso de interacción entre sujetos políticos y de relación entre las diversas dimensiones de la vida social, que mediados por la circulación de sentidos buscan la construcción de otros saberes y aprendizajes colectivos. Ahora, si bien el diálogo es una acción real y por ende la comunicación es un asunto clave para tal fin, también lo es el hecho que para construir lo público se requiere de ciudadanos interesados en ese escenario. Es decir, acogiéndonos a los planteamientos de Jorge Iván Bonilla (2007), el intercambio comunicativo entre ciudadanos que deliberan, es tan sólo uno de los tantos caminos para acceder a la esfera pública. Esto significa que para ser parte de la esfera pública se necesita llevar adelante prácticas e intercambios comunicativos como también reconocer, tal como lo mencionamos antes, la diferencia. Es por ello que para Bonilla,

La historia de la formación de la esfera pública moderna es también la historia de las exclusiones de aquellos sectores asociados con lo popular, lo inferior y lo marginal. De ahí que la relación género-raza-clase fuera fundamental para construir los límites del debate público (Bonilla, 2007, p. 8). 
De ahí que la esfera pública, en su opinión, tanto en el pasado como en nuestro presente, se esté construyendo a partir de conflictos. Lo que quiere decir que no existe una sola ni un solo tipo de ciudadano o ciudadana legitimados para actuar y para habitar en ella. Interpretamos "que una de las funciones fundamentales de la comunicación es la visibilización de la democracia y de los ciudadanos. Aquí entramos en el asunto del reconocimiento" (Rocha, Moreno, Molina, y Ortiz, 2008, p. 90). Por tanto, la comunicación vista como proceso, es el vehículo a través del cual se pueden vincular y/o acortar distancias entre las expresiones individuales con las manifestaciones públicas.

Sumado a ello, consideramos que "los medios hoy tienen la misión de contribuir a construir lo común” (Rocha, Moreno, Molina, y Ortiz, 2008, p. 90), pero también creemos que lo común en nuestros días está cargado de incertidumbres aunque sabemos que compartimos conflictos de toda índole. Estos se encuentran inscritos en nuestras cotidianidades y los mismos, requieren de un ejercicio constante de análisis, con el fin de generar acciones para el cambio. En esa dirección, los medios tienen la responsabilidad de ayudar a identificar y comprender los puntos de encuentro y desencuentro, sus detalles y características asumiendo con ello, el compromiso con los asuntos públicos.

El desarrollo social y humano y la construcción del campo de lo público son procesos complementarios, tejidos entre sí. Toda acción del desarrollo se sitúa en la dimensión de lo público, pues en ella tienen lugar relaciones e interacciones inter/subjetivas complejas. Entonces, los elementos constitutivos de la comunicación y el desarrollo en la construcción de lo público habitan en los procesos, la participación política ciudadana y en la circulación de saberes, lo cuales se basan en la cooperación y la confianza que convergen en una práctica con sentido.

\section{El contexto del Chocó: un pasado irremediable}

Al margen de las costas del Océano Pacífico colombiano se encuentra ubicado Chocó, uno de los sitios más ricos de Colombia por su biodiversidad y por ser uno de los pulmones del planeta. Estas características -que debieran generar el mayor de los beneficios a sus ciudadanos-, se han convertido en el objetivo de quienes establecen las formas de imponer sus intereses. El narcotráfico, las bandas delincuenciales hasta la explotación de minas ilegales son algunos ejemplos que nos permiten observar cómo se destruye el ecosistema y los ríos, amenazando la vida de los habitantes del Chocó, y en particular del departamento de Quibdó, que son fundamentalmente indígenas y afrocolombianas.

Esta población vive en condiciones económicas y sociales difíciles, ligadas a flagelos como: el desplazamiento de los lugares de origen, secuestros, amenazas y homicidios; una infraestructura vial que aísla al departamento y lo deja por fuera de las dinámicas del comercio del país. Junto a ello, la presencia de grupos ilegales, desde guerrillas hasta narco/ paramilitares y bandas criminales, causan desplazamientos forzados. A esto se suman los servicios públicos inadecuados, el analfabetismo con una tasa que duplica a la nacional y un precario sistema de salud, reflejado en carencia de medicamentos, deficientes condiciones de infraestructura, y falta de ambulancias equipadas. Situaciones que se fueron fomentando en un pasado irremediable y naturalizado por quienes habitan en la región. Si 
bien estos grupos han sido y son olvidados por el Estado, para Alianza Urbana son materia de inspiración para resistir los embates de la realidad, a través de su música.

\section{Análisis colectivo del pasado y la incidencia política de Alianza Urbana}

El proyecto Alianza Urbana está conformado por jóvenes cantantes de barrios populares de Quibdó que viven en contextos de vulnerabilidad. La campaña "Alza tu voz, alza tu cuerpo" fue el impulso inicial que dio vida a este colectivo. Promovida por el equipo "Los Inquietos", este proyecto -junto con otros realizados por ellos- trabajó con ciertos barrios periféricos desde donde se buscó abrir y mantener diálogos con los jóvenes que estaban involucrados o que están en riesgo de ser utilizados por grupos delictivos y o específicamente del narcotráfico que están siendo parte de la vida cotidiana en los barrios en Quibdó. Miguel Copete, uno de los integrantes, nos cuenta:

Creo que el aporte de Alianza Urbana al pueblo quibdoseño y en general a Colombia es la de visibilizar problemáticas, pero además de visibilizarla se trabaja el tema de la conciencia, se hace énfasis en que están sucediendo cosas y no se están dando cuenta. El Chocó no es solamente lo que dicen los medios, si padecemos problemáticas pero también proponemos. Alianza Urbana no sólo es denuncia también propone en cada una de sus letras. Hay gente que no es amante de la música urbana pero cuando escucha una canción del grupo, sabe que hay un trabajo y una apuesta política, eso merece la pena. El reconocimiento que Alianza Urbana ha recibido de muchos sectores sociales muestra que el grupo está dejando huella, está dejando un conocimiento (Copete, 2015) ${ }^{1}$.

En la entrevista realizada, Miguel afirma que uno de los logros de la Alianza Urbana es que a lo largo de su proceso de conformación y consolidación, los jóvenes integrantes han ido adquiriendo capacidad crítica y propositiva frente a las problemáticas de Quibdó. Para ello, investigan en profundidad las temáticas que luego, de forma colectiva, plasman e interpretan en sus canciones. Este devenir político y participativo ha fortalecido su capacidad discursiva y deliberativa y su sentido de apropiación ya que, "han abierto espacios donde ellos se sientan a dialogar sobre temas de violencia y respeto a la vida con otros actores sociales dentro y fuera del departamento; con ello se construye un diálogo de saberes y por ende otros conocimientos" (Copete, 2015).

Para la coordinadora y cooperante de la Alianza Urbana, Michaela Pfister, la juventud en Quibdó se encuentra invisibilizada por los medios y con un grado mínimo de inclusión y participación, por parte de las instituciones del Municipio. "Hay muchos asesinatos, un desempleo elevado, la educación es mala, aquí uno podría nombrar y nombrar problemas. Todo el mundo quizás inconscientemente lo sabe o lo ha escuchado, pero no existe ningún espacio para el debate de esos problemas" (Pfister, 2015)².

El reto con Alianza Urbana fue y sigue siendo, el de construir mediante la música un modo de visibilización de las problemáticas de la juventud. "Quizás el rap no es un género reconocido en Quibdó como música, sin embargo los videos de las canciones ayudan a que 
se debatan las problemáticas entre los mismos jóvenes y la sociedad en general" (Pfister, 2015).

La incidencia política de este colectivo artístico en las mesas donde se construyen políticas públicas aún no se ha generado. Pfister cree que es un camino muy largo a transitar pero, en su opinión, la participación de los jóvenes en la construcción de políticas públicas es algo que proyectan como grupo a largo plazo. Por eso, piensa que el conjunto musical deja su impacto porque,

Los videos es algo que todos quieren ver porque es hecho acá, eso lo hace atractivo, la gente quiere mirar a la gente que conoce. En la misma juventud ha dejado una fuerte huella, porque invita a los jóvenes a pensar en cosas importantes. Es un producto que muestra qué piensan los jóvenes, qué problemáticas sufren y también qué ideas tienen los jóvenes para solucionarlas (Pfister, 2015).

Con este marco, surge la pregunta sobre cómo se construyen las canciones de Alianza Urbana. Para Pfister (2015), lo primero tiene que ver con el interés de los jóvenes.

Ellos hablan con el equipo coordinador y plantean la temática, la función del equipo coordinador es la de facilitar los elementos técnicos como la computadora y espacios de discusión, también orientan el desarrollo del tema, proporcionando material de análisis. El propósito es que todos, a través de la investigación realizada, se hagan una visión más global y conozcan el origen de la problemática de la cual están hablando (Pfister, 2015).

Con ella conversamos acerca de los logros del colectivo. Pfister entiende que los mismos tienen que ver con las producciones audiovisuales.

Allí los jóvenes se expresan sobre las temáticas fundamentales, no sólo de la juventud sino también del Chocó de una menara muy creativa, sin perder que son historias reales de sí mismos. Cuentan su realidad. El grupo se ha hecho muy conocido en Quibdó, en algunas partes de Colombia y Alemania (Pfister, 2015).

Otra meta alcanzada radica en el involucramiento de los jóvenes en campañas pedagógicas en los colegios.

Cada uno de los integrantes del grupo ya tiene su grupo personal, muchos trabajan con niños o jóvenes de menos edad, en ese sentido son también multiplicadores porque todos los conocimientos y experiencias que ellos han obtenido en el proceso y a través de su realidad lo comparten, en esa medida son también líderes de otros procesos (Pfister, 2015).

Como notamos en estos diálogos y en nuestras consideraciones conceptuales, la comunicación y el desarrollo son escenarios de encuentro y participación donde la política adquiere una dimensión sustancial porque lo que se pone en juego es el ámbito público, 
y con ellas posturas, intereses y objetivos que son, en últimas, formas inter/subjetivas de ver la realidad para transformarla. Pero cómo analizar aquí este tipo de comunicación. Creemos en una comunicación que propicia la reflexión y la deliberación sobre los asuntos públicos; en una comunicación que permite a los sectores excluidos su reivindicación y legitimación política.

En tanto proceso, la comunicación es un devenir constante de interacción entre sujetos políticos y de relación entre las diversas dimensiones o campos de la vida social, que siendo mediados por sus prácticas y la circulación de sentidos buscan la construcción de otros conocimientos y aprendizajes colectivos. La Alianza Urbana mantiene una comunicación que gira, a su vez, sobre dos dimensiones. La primera de ellas se encuentra en el plano interno como grupo; es decir, las interacciones construidas entre sus integrantes, en la que todo el tiempo transitan sentidos, experiencias y aprendizajes colectivos con disensos y consensos. Segundo, en el plano externo, a través de la música. Aquí vemos que sus letras son construidas estratégicamente, producto de un proceso crítico de investigación y reflexión que busca posibilitar la promoción de procesos de interacción social para la toma de decisiones colectivas.

El rap que el grupo produce es sólo el medio discursivo por donde transitan sus mensajes (Verón 1987). De fondo, su contenido intenta propiciar la reconstrucción de lo público y desencadenar procesos de formación ciudadana. Cada uno de los integrantes de Alianza Urbana se piensan así mismos y como grupo, en relación con los demás actores de la sociedad. Tanto la música como sus videos logran registrarse -en el contexto quibdoseño-, básicamente por tres razones. La primera, porque los temas abordados manifiestan un presente singular de conflictos, en diálogo sostenido con las problemáticas territoriales de antaño. Segunda, gracias a la música pasaron de ser receptores a protagonistas y productores de mensajes. Y tres, a través de la imagen en sus videos, la comunidad chocoana junto a cualquier ciudadano del mundo que tenga acceso a Internet tienen la posibilidad de ver experiencias temporales diversas de una realidad marginada y no atendida por aquellos que tienen la responsabilidad de hacerlo.

La canción "Barreras invisibles" es un ejemplo que retrata la posición como grupo sobre el conflicto de las fronteras que invisibilizan a los jóvenes en Quibdó, producto de la guerra entre pandillas y comandos armados que hacen presencia en la región. A continuación un fragmento:

Se enfrentan uno a otros - por ganar más territorio.

Que conducen a familias a quedar tristes y solos.

Se siembra temor - discordia en las calles.

No pasen por aquí - o sino bala les cae.

No se gana el respeto - se acaba muchas vidas.

Se pierde un amigo - un hermano, una familia.

No se gana el respeto - se acaba muchas vidas.

Se pierde un amigo - un hermano, una familia.

Para ellos, Quibdó es una ciudad presente de violencia y desequilibrio económico, político, y cultural que abarca a la región. Una ciudad donde el accionar del tiempo provocó 
-entre otras variables-, una actitud de sumisión en su población campesina y afrodescendiente provocando con ello un estado sub-desarrollado imperdurable. Una ciudad sin un futuro estratégico y planificado. El proceso artístico busca fortalecer esta mirada, a partir de la revalorización de sus tradiciones locales y las materialidades productivas históricas expresadas en sus canciones. Con ello se intenta que otros muchos jóvenes "rompan el silencio". Romper el silencio es el objetivo principal que tienen los integrantes de Alianza Urbana, en pro de crear música urbana para resistir a los problemas de su cotidianidad aportando así, una consciencia crítica para la paz social. La música urbana es un instrumento de resistencia a la violencia y a los problemas cotidianos utilizando la creatividad como recurso y la voz como medio para la protesta pacífica es una expresión de liberación, aprendizaje, dinamización y transformación.

Lo que empezó como un pasatiempo para unos jóvenes, hoy es un motivo de vida, una familia que actúa junta y que pretende desde su accionar reconfigurar los pensamientos y acciones de quienes los escuchan, a pesar de que tanto los unos como los otros estén en condiciones sociales precarias por la llamada "violencia estructural". Este grupo de rap es ejemplo de que no es el asistencialismo lo que hace que las sociedades se transformen sino el empoderamiento y el trabajo colectivo.

De tal manera, los conflictos sociales e interpersonales son el motor de la participación, en la escena pública. Su poética, atravesada por temporalidades diversas, propicia la comprensión del contexto chocoano y contribuyen a entender las racionalidades individuales y colectivas que rodean sus conflictos presentes. No obstante, creemos que sus esfuerzos requieren vincular la dimensión social con la dimensión política de Quibdó, que es donde se toman las decisiones. Es necesario que su música trascienda la reflexión colectiva y generé la articulación de otros actores sociales para la organización de acciones políticas sobre sus conflictos más sentidos.

\section{Consideraciones finales}

A partir de los relatos obtenidos y en articulación con los estudios sobre lo público y el desarrollo, sostenemos que el objetivo de "Alianza Urbana" es el de incidir en el progreso social y humano y en la reconstrucción de lo público, en el departamento de Quibdó. Lo común en ellos, además de convivir en un mismo espacio/temporal, también lo es el placer generado por la música y su preocupación por los conflictos que azotan la región. Durante el trabajo de campo, notamos que "Alianza Urbana" transita simultáneamente entre las dos esferas pública y privada. En la primera, porque a través de su música narran sus temporalidades experienciales constituyéndose desde la producción y circulación de la misma como ciudadanos políticamente activos. Pero dado que necesitan financiar sus discos y obras audiovisuales, en algunos casos, logran financiamiento de organizaciones alivianando sus compromisos económicos. La pregunta que surge es: ¿puede la esfera pública constituirse desde la privada?

Para Marco Navas Alvear "la participación en lo público se presenta en dos dimensiones, al menos: una dialógica-reflexiva y otra de visibilidad” (Navas Alvear, 2012, p. 74). Como lo hemos resaltado durante este trabajo, consideramos que la dimensión dialógica-reflexiva 
se refleja en el ejercicio habitual del grupo de dos maneras. La primera, en la construcción de la letra de sus canciones. En ella, discuten colectivamente el tema que quieren abordar, investigan mediante entrevistas en los barrios y consultas de material impreso y digital, luego deliberan sobre el material recogido y postura frente al mismo, para finalmente iniciar con el proceso de escritura de la letra de la canción.

La participación brinda la posibilidad de incidir en el diálogo y la reflexión en la escala social. Allí, los integrantes del grupo intervienen en lo público, pues han hecho pensar, dialogar y debatir a la comunidad sobre los temas que los afecta. No obstante, reconocen que una de sus debilidades se encuentra en la política, ya que no han logrado penetrar, como colectivo de trabajo, con sus canciones y propuestas, en el sistema partidario de Quibdó. Saben que uno de los mecanismos para hacerlo se encuentra en la construcción de políticas públicas de juventud. Lo que les brindaría una participación más activa y con mayor posibilidad de transformación, en los distintos niveles del estado departamental. Para concluir, podemos decir que lo público es una dimensión espacial -en tanto organismos que lo integran-, y temporal, en función de las experiencias particulares y colectivas en constante tensión, causadas por las luchas de poder entre los diversos actores y sectores que la componen. En ese sentido, lo público es resultado de múltiples y simultáneos procesos, que a su vez son dinámicos, en los que se ponen en juego diversos puntos de vista y distintas maneras de accionar en un mismo espacio/temporal.

La construcción de lo público requiere de una ciudadanía interesada en ello y con opción de fortalecer la participación individual y colectiva de manera organizada. Por tanto, la organización política y el análisis colectivo de conflictos territoriales, requieren de un ejercicio constante de contextualización y análisis donde el tiempo y las expresiones estéticas -en este caso la música rap-, son acto y memoria de una consciencia crítica juvenil que pretende incidir en la esfera pública para trabajar en lo real sin dejar que la imaginación desaparezca.

\section{Notas}

1. Entrevista realizada a Miguel Copete (abril de 2015) durante la primera salida de campo del equipo de investigación de Uniminuto.

2. Entrevista a Michaela Pfister (abril de 2015). Pedagoga social y cooperante alemana. Hace cinco años y medio trabaja como cooperante internacional con la diócesis de Quibdó en el tema de jóvenes en alta vulnerabilidad. Jóvenes en medio de reclutamiento, delincuencia y drogadicción. La agencia para la cual trabaja es la AGH (Asociación de los católicos alemanes).

\section{Referencias bibliográficas}

Alfaro, R. M. (2015). Una comunicación para otro desarrollo. Lima, Perú: Ed. CALANDRIA. Arendt, H. (1993). La Condición Humana. Barcelona, España: Ed. Paidos.

Barbero, J. M. (2001). De los medios a las mediaciones. Comunicación, cultura y hegemonía. Barcelona, España: Ed.Gustavo Gili. 
Bautista, J. (2003). “Sobre lo público y los ingresos públicos”. En C. Giraldo, Rescate de lo público. Poder financiero y derechos sociales. Bogotá, Colombia: Ed. Desde Abajo.

Beltrán, L. R. (2005). "La comunicación para el desarrollo en Latinoamérica: un recuento de medio siglo”. En, III Congreso panamerica de la comunicación. Buenos Aires, Argentina: Ed. Universidad de Buenos Aires.

Bonilla, J. I. (2007). Lo público en los medios. Reflexiones sobre comunicación, política y ciudadanía. Recuperado de: www.c3fes.net

Camacho, C. A. (2007). Las radios populares en la construcción de ciudadanía: enseñanazas de la experiencia de la ERBOL en Bolivia. Recuperado de: http://www.monografias. $\mathrm{com} /$ trabajos-pdf4/radios-populares-construccion-ciudadania/radios-popularesconstruccion-ciudadania.pdf

De Certeau, M. (1994). La invención de lo cotidiano, habita, cocinar. México. Ed: Universidad Iberoamericana.

Cortes, J. J. (2015). Cultura y comunicaciòn como praxis para el desarrollo. Recuperado de: www.hegoa.ehu.es/congreso/gasteiz/doku/JuanjoCortes.pdf

Falconí, F. (2014). Al sur de las decisiones. Enfrentando la crisis del siglo XXI. Quito, Ecuador: Ed. El Conejo.

Franco Cháves, F. P., y López Rojas, A. M. (2011). "Una mirada a las raíces de la comunicación para el desarrollo”. Entrevista con Luis Ramiro Béltran Salmón, en Revista Signo y Pensamiento. Recuperado de: http://revistas.javeriana.edu.co/index.php/signoypen samiento/article/view/2472

Fraser, N. (2015). Repensando la esfera pública. Una contribución a la crítica de la democracia actualmente existente. Recuperado de: http://estudios.sernam.cl/img/upoloads/ fraser_esfera_publica.pdf

Gumucio, A. (2011). “Comunciación para el cambio social: clave del desarrollo participativo”. En: Comunicación, desarrollo y cambio social (2011). Bogotá, Colombia: Ed. Pontificia Universidad Javeriana.

Habermas, J. (2008). Teoría de la acción comunicativa, II. Madrid, España. Ed. Taurus.

Herrera, E., y Vega, J. ( 2012). Xl Congreso latinoamericano de investigadores de la comunicación ALAIC 2012. Recuperado de: http://alaic2012.comunicacion.edu.uy/content/ pr\%C3\%A1cticas-comu

Mokus, A. (2002). "La ciudad y lo público”. En: Comunicación para construir lo público. Bogotá, Colombia: Ed. Pontificia Universidad Javeriana, Convenio Andres Bello.

Navas Alvear, M. (2012). Lo público insurgente. Crisis y construcción de la política en la esfera pública. Quito, Ecuador: Ed. CIESPAL.

Pécaut, D. (2015). Crisisy construcción de lo público. Recuperado de: http://200.93.163.76:8080/ moodledata9/34/Lecturas/Crisis\%20de\%20lo\%20Publico\%20-\%20Pecaut.doc.

Rocha, C., Aldana, Y., y Rodríguez, L. (2013). Los conflitos y su gestión en la radio escolar. Medellín, Colombia: Ed. Universiad Pontificia Bolivariana.

Rocha, C., Moreno, E., Molina, I., y Ortiz, G. (2008). Comunicación para la construcción del capital social. Bogotá, Colombia: Ed. UNIMINUTO.

Rocha, C., Rodríguez, L. C., y Aldana, Y. (2012). "El reconocimiento como base de la comunicación entre distintos". Congreso ALAIC. Recuperado de: http://www.alaic.org/site/ congresos/congreso-alaic-2012/?lang=es 
Rodríguez, C. (2009). “De medios alternativos a medios ciudadanos: Trayerctoria teórica de un término”. Recuperado de: http://aprendeenlinea.udea.edu.co/revistas/index.php/ folios/article/viewFile/6416/5898

Seen, A. (2000). Desarrollo y libertad. Bogotá, Colombia: Ed. Planeta.

Verón, E. (1987). "La semiosis social. Fragmentos de una teoría de la discursividad". Recuperado de: http://fba.unlp.edu.ar/lenguajemm/?wpfb_dl=6

Résumé : Chocó est un département colombien qui s'est trouvé au cœur d'une profonde crise humanitaire. Dans sa capitale, Quibdó, un groupe de jeunes a créé le programme «Alza tu voz», qui a donné naissance au groupe musical "Alianza Urbana». Le présent texte cherche à exposer du point de vue de la communication, les stratégies artistiques et pédagogiques mises en place par ce collectif pour générer des alternatives de vie, dans un territoire où les jeunes semblent figés dans le temps, mais résistent aux situations du passé avec des rythmes contemporains.

Mots clés : Communication - Développement et changement social - Reconstruction du public - Pratiques communicatives.

Abstract: Chocó is a Colombian department that has lived in the middle of a deep humanitarian crisis. In his capital, Quibdó, a group of young people create the program "Alza tu voz", from there the music group "Alianza Urbana" was born. The present text seeks to expose the way in which this artistic and pedagogical strategy constituted by this group, from the perspective of communication and development for social change, is able to generate alternatives of life in a territory in the which young people seem to be stagnating in time, resisting situations of the past with contemporary rhythms.

Keywords: Communication - Development and Social Change - Reconstruction of the Public - Communicative Practices.

Resumo: Chocó es un departamento colombiano que ha vivido em meio de uma crise profunda humanitaria. En su capital, Quibdó, um grupo de jovens crean o programa "Alza tu voz", de lá o grupo de música "Alianza Urbana". O presente texto busca exponer a forma pela estratégia estatica artística e pedagógica constituída por este grupo, desde a perspectiva da comunicação e do desenvolvimento para o cambio social, é capaz de gerar alternativas de vida em un territorio en el que os jovens parecem estancados no tempo, fazendo resistência a situações do passado com ritmos contemporáneos.

Palavras chave: Comunicación - Desenvolvimento e Cambio Social - Reconstrução do Público - Prácticas Comunicações.

[Las traducciones de los abstracts al francés, inglés y portugués fueron supervisadas por el autor de cada artículo] 